Review

\title{
Genetic Variation in Caenorhabditis elegans Responses to Pathogenic Microbiota
}

\author{
Yuqing Huang (i) and Jan E. Kammenga *(1) \\ Laboratory of Nematology, Wageningen University, Droevendaalsesteeg 1, 6708 PB Wageningen, \\ The Netherlands; yuqing.huang@wur.nl \\ * Correspondence: jan.kammenga@wur.nl; Tel.: +31-317-482-998
}

Received: 1 April 2020; Accepted: 22 April 2020; Published: 24 April 2020

\begin{abstract}
The bacterivorous nematode Caenorhabditis elegans is an important model species for understanding genetic variation of complex traits. So far, most studies involve axenic laboratory settings using Escherichia coli as the sole bacterial species. Over the past decade, however, investigations into the genetic variation of responses to pathogenic microbiota have increasingly received attention. Quantitative genetic analyses have revealed detailed insight into loci, genetic variants, and pathways in C. elegans underlying interactions with bacteria, microsporidia, and viruses. As various quantitative genetic platforms and resources like C. elegans Natural Diversity Resource (CeNDR) and Worm Quantitative Trait Loci (WormQTL) have been developed, we anticipate that expanding C. elegans research along the lines of genetic variation will be a treasure trove for opening up new insights into genetic pathways and gene functionality of microbiota interactions.
\end{abstract}

Keywords: Caenorhabditis elegans; microbiota; genetic variation

\section{Caenorhabditis elegans Responses to Microbiota}

Caenorhabditis elegans (Nematoda; Rhabditidae) is a cosmopolitan hermaphroditic nematode that thrives on bacteria in rotting plant material [1,2]. It was introduced as a tractable species for biological research during the early 1970s [3], and since then, it has been established as a widely used model species in biological research. As a bacterivorous nematode, C. elegans populations can easily be reared in the lab. Research using C. elegans has mainly investigated nematodes kept under axenic laboratory conditions (i.e., populations are maintained in petri dishes at $20^{\circ} \mathrm{C}$ on agar plates seeded with Escherichia coli as a food source) that are devoid of interactions with natural pathogens. Microbiota provide C. elegans with nutrients, but they may also be pathogenic, leading to decreased growth and fitness of nematodes [4]. Over the past few years, there has been a growing interest in unraveling the interaction between C. elegans and its pathogenic microbiota, like microsporidia, bacteria, and viruses, with the aim to better understand C. elegans ecology away from E. coli $[5,6]$. The C. elegans microbiota community normally inhabits or is closely associated with the nematode [7]. Recently, it was reported that the microbiota are able to synthesize essential nutrients for C. elegans and that the microbiota assembly is highly dynamic in time and species composition [8]. Understanding the interactions between C. elegans and microbiota may help further in gaining a deeper insight of microbiota interactions in other species. This comes at an important moment since it is increasingly realized that microbiota play in an important role in metazoan health [9].

\section{Genetic Variation in Caenorhabditis elegans as the Basis to Understand Microbiota Interactions}

The vast majority of $C$. elegans microbiota studies are host-pathogen interaction studies and have been limited to elucidating the molecular mechanism of host-pathogen interaction using a single C. elegans wild type strain, the canonical strain Bristol N2 [10]. Yet, studying genetically 
variable $C$. elegans strains will provide a broader view on the genetic architecture of host-pathogen interactions (Table 1). Over the past two decades, C. elegans has been established as a platform for studying the genetic architecture of complex traits using quantitative genetic analyses based on genetic variation [11,12]. A range of complex phenotypes have been mapped to loci and genetic variants using genetic linkage studies or genome-wide association approaches [13]. The C. elegans Natural Diversity Resource (CeNDR) was established to collect all genetic and genomic studies based on wild strains, thus facilitating genome-wide association studies (GWAS) [14]. It is a comprehensive data platform showing the genetic variation of $C$. elegans worldwide and facilitating genome-wide association analyses. Worm Quantitative Trait Loci (WormQTL) was recently launched, a platform for systems genetics in C. elegans [15]. Next to this, genetic resources such as recombinant inbred line (RIL) populations and introgression line (IL) populations derived from wild type Bristol N2 and Hawaii CB4856, or other wild strains, were constructed to unravel quantitative trait variants or genetic architectures [16]. For instance, two multiparent RIL panels were constructed derived from either four or eight parental wild strains. The quantitative trait loci (QTL) mapping panel C. elegans eight parental experimental evolution (CeMEE) contains more than 500 RIL. CeMEE has already been applied in C. elegans research to understand the genetic basis of complex phenotypes, like fertility and the hermaphrodite body size during reproduction [11,13,17]. Another four parental population of recombinant inbred lines was derived from wild type strains that together captured genetic variation on a local scale [13]. Several studies using a range of these genetic resources have been used to study the genetic variation regarding the C. elegans-microbiota interactions (Table 1). These studies will be discussed in more detail below.

Table 1. Quantitative genetic studies of C. elegans-microbiota interactions.

\begin{tabular}{|c|c|c|c|c|}
\hline Microbiota & Species & Phenotypes & $\begin{array}{l}\text { Strains of } \\
\text { C. elegans }\end{array}$ & Reference \\
\hline \multirow[t]{3}{*}{ Bacteria } & B. thuringiensis & $\begin{array}{l}\text { Behavior response (evasion and } \\
\text { reduced parasite ingestion) }\end{array}$ & $\begin{array}{l}\text { Ten wild strains; } \\
\text { RILs and ILs }\end{array}$ & [18] \\
\hline & P. aeruginosa & $\begin{array}{c}\text { Behavior response } \\
\text { (oxygen-dependent behavioral } \\
\text { avoidance) }\end{array}$ & RILs and ILs & [19] \\
\hline & S. marcescens & Odor attractiveness & CB4856 and N2 & [20] \\
\hline \multirow[t]{2}{*}{ Microsporidia } & N. ironsii & $\begin{array}{l}\text { Ability of clearing infection; initial } \\
\text { colonization of Nematocida }\end{array}$ & CB4856 and N2 & {$[21,22]$} \\
\hline & N. ironsii & Resistance in young L1 larvae & CB4856 and N2 & [21-23] \\
\hline Virus & Orsay virus & Susceptibility & $\begin{array}{l}\text { N2 and JU1580; } \\
\text { ILs (GWAS) }\end{array}$ & [24] \\
\hline
\end{tabular}

RIL: recombinant inbred lines; IL: introgression lines; GWAS: genome wide association study.

\section{Caenorhabditis elegans-Bacteria Interactions}

Of all C. elegans microbiota groups, bacteria are the most well studied. Bacteria may serve as food and/or may be pathogenic to C. elegans. The most abundant bacteria studied include Gammaproteobacteria (Enterobacteriaceae, Pseudomonaceae, and Xanthomonodaceae) and Bacteroidetes (Sphingobacteriaceae, Weeksellaaceae, and Flavobacteriaceae) complemented with a few Acetobacteriaceae [25,26]. Proteobacteria, Bacteroidetes, Firmicutes, and Actinobacteria are bacterial phyla found living in the same habitat as C. elegans [27]. C. elegans populations thrive well on these bacteria, and some of these bacteria may even increase resistance to abiotic and biotic stress factors, including pathogen infection [25,28]. C. elegans is able to avoid the pathogenic bacteria, Pseudomonas aeruginosa, through aversive olfactory learning. This ability could be transmitted to next generations under the function of P-element Induced WImpy testis (Piwi) Argonaute homolog Piwi Related Gene (PRG-1), thus improving the fitness of the progeny [29]. Besides, innate pathways are also under investigation [30]. Pseudomonas vranovensis is a natural pathogen of $C$. elegans, parental exposure of $C$. elegans to $P$. vranovensis upregulates the cysteine synthases CYSL-1 and CYSL-2 and the regulator of hypoxia inducible factor RHY-1, which promotes 
the resistance of progeny to infection [31]. Besides variant strains, sex differences in C. elegans also have impact on the resistance to Bacillus thuringiensis [32]. Under infection pressure from B. thuringiensis, males of $C$. elegans have lower resistance and survival than hermaphrodites. Next to this, proteome levels in C. elegans differ depending on the type of bacteria that they feed on [10], like Ochrobactrum spp. (MYb71, MYb237) or E. coli OP50.

Schulenburg and Muller (2004) showed that genetic variation affects infection of C. elegans by a parasitic strain of Gram-positive B. thuringiensis using ten wild strains [18]. Their analyses revealed genetic variation for behavioral responses as an important defensive factor in C. elegans. Here, the behavioral trait comprised evasion and reduced parasite ingestion. As for the gene level, different quantitative genetic studies have identified the neuropeptide $\mathrm{Y}$ receptor gene, $n p r-1$, as a major pleiotropic determinant regarding bacterial food intake. Natural variation in $n p r-1$ was first reported to modify social behavior and responses to food [33]. Later, it was reported that polymorphic npr-1 affected behavioral responses to the Gram-negative pathogen Pseudomonas aeruginosa by means of oxygen-dependent behavioral avoidance rather than direct regulation of innate immunity [19]. Nakad et al. (2016) investigated the role of $n p r-1$ in C. elegans exposed to B. thuringiensis and P. aeruginosa using QTL analyses of behavioral immune defense and RNAseq-based transcriptomics using recombinant inbred lines and introgression lines [34]. Several QTL were detected, including one on chromosome X harboring $n p r-1$. The wild type $\mathrm{N} 2$ allele was found to be associated with reduced defense against B. thuringiensis and had an opposite phenotype to that previously mapped for the N2 npr-1 allele against $P$. aeruginosa. Global gene expression profiling suggested that $n p r-1$ plays an important role against both pathogenic bacteria through p38 Mitogen-Activated Protein kinases (MAPK) signaling, insulin-like signaling, and C-type lectins.

The reduced sensitivity to $P$. aeruginosa was associated with the induction of oxidative stress genes and activation of GATA transcription factors. In contrast, oxidative stress gene suppression combined with the activation of Ebox transcription factors determined B. thuringiensis effects. Like npr-1, genetic variation in other genes related to neuronal functions was found to play a key role in detecting food related cues, like tyramine receptor gene tyra-1, encoding a $G$ protein-coupled catecholamine receptor [35]. Interestingly, $n p r-1$ was found to control a range of phenotypic differences through behavioral avoidance of ambient oxygen concentrations to growth and physiology. Together, these results show that genetic variation in $n p r-1$ gives rise to pleiotropic effects that are associated with bacterial food [36].

Next to $n p r-1$, Chang et al. (2011) found polymorphisms in a Homologous to the E6-AP Carboxyl Terminus (HECT) domain-containing E3 ubiquitin ligase, HECW-1. Two polymorphisms close to residues of HECW-1 each affected C. elegans behavioral avoidance exposed to P. aeruginosa [37]. The resistance of $C$. elegans to P. aeruginosa is achieved by avoidance instead of physiological stress pathways. Neuronal analysis pointed out that HECW-1 functions in two of sensory neurons against P. aeruginosa through inhibition of the neuropeptide receptor NPR-110.

In C. elegans-bacteria interaction studies, QTL analysis was not only used to study npr-1, but also to detect other genetic variants. For example, it was found that the ability of $C$. elegans to sense bacteria also differed among the different strains of $C$. elegans. The odor of Serratia marcescens is more attractive to Bristol N2 than Hawaii CB4856. In this case, QTL analysis helped to define the region that interacts and affects S. marcescens preference based on RILs [20]. In summary, genetic variation study of $C$. elegans-microbiota systems were mostly researched in bacteria until now. The results varied from gene level to behavior level, expanding the insight into different host mechanisms in C. elegans against bacterial pathogen.

\section{Caenorhabditis elegans-Microsporidia Interactions}

Microsporidia are a group of eukaryotic intracellular pathogens comprising more than a thousand species that are associated with a wide host range [38]. Nematocida parisii was the first microsporidian species found to infect $C$. elegans and causes lethal infections. The mechanism of microsporidia to 
invade host tissue is mainly achieved by restructuring multicellular host tissues into syncytia and proliferating cells across the host tissue cells before forming spores [39]. As N. parisii has been isolated from wild C. elegans, C. elegans-N. parisii interactions have become an important model for studying both the infection process of pathogen and response of the host. The response of $C$. elegans to N. parisii involves a transcriptional response named intracellular pathogen response (IPR) that can be triggered by proteotoxic stress to improve the resistance to the stress [40]. This response results in upregulation of 80 so-called IPR genes regulated by genes pals-22 and pals-25 [41]. Whilst studying natural pathogens of C. elegans including microsporidia, it was found that IPR involves gene pals-22 and pals- 25 which play an essential role in combatting pathogens. Mutation of pals-22 showed increased resistance to microsporidia infection as well as virus infection. However, mutants of pals-25 showed suppressed phenotypes caused by mutation in pals-22, including increased IPR gene expression, thermotolerance, and immunity against natural pathogens. Gene pals-22 was proved to repress expression of some ubiquitin ligase complex components and other IPR genes [41].

Microsporidia are transmitted horizontally and replicate predominantly in intestinal cells in $C$. elegans. However, among different species of microsporidia, host range [42], virulence [39], and tissue tropism strongly differ [43]. For example, N. parisii only invades and replicates in the intestinal cells of C. elegans, while Nematocida displodere is able to infect multiple host tissues [43]. Besides, some IPR genes regulated by N. parisii in C. elegans were hardly induced by Nematocida ausubeli, suggesting it may evolve to counteract with the host response [42]. In the meantime, among different species of nematodes, their responses to microsporidia are not the same as well. For instance, after three days of infection, for C. elegans and C. briggsae, 50\% of the worms were infected, while for Oscheius tipulae, no infectious behavior was found [42].

Genetic variation in epithelial immunity was found in C. elegans after infection of the intestines by Nematocida ironsii [21-23]. Wild type CB4856 displayed a higher clearing and resistance to infection than wild type Bristol N2, and this difference was specifically found in their young larvae. It was concluded that this antagonistic pleiotropic effect in CB4856 enables a higher progeny later in life and leads to a selective advantage under laboratory conditions. In the study, resistance was mapped to four genomic loci, and two of these loci influencing resistance were confirmed [23]. Overall, the quantitative genetic study revealed that resistance to microsporidia early in the life of $C$. elegans is a complex trait associated with higher reproductive output later in life, thus enhancing overall fitness. Currently, only a few genetic variation studies of microsporidia infections in C. elegans have been conducted. More research into the genetic variants affecting epithelial tolerance is required since the epithelium plays a major role in host-pathogen interactions.

\section{Caenorhabditis elegans-Virus Interactions}

Studies on C. elegans-virus interactions were hampered by the lack of a naturally infectious virus until 2011 when Orsay virus was found [24,44]. Orsay virus is a single-stranded RNA (ssRNA) positive-strand virus related to the family Nodaviridae [45]. It is the first virus found to naturally intracellularly infect and complete its whole life cycle in C. elegans intestinal cells [24,46]. Orsay virus consists of two segments: the RNA1 segment encodes viral RNA-dependent RNA polymerase (RdRP), and the RNA2 segment encodes capsid protein and one additional open reading frame (ORF) of 332 amino acids at $3^{\prime}$ end called delta (ORF $\delta$ ) [46,47]. ORF $\delta$ is important for nonlytic viral egress $[48,49]$. Contrary to most Nodaviruses, Orsay virus does not contain a RNA-3 translated suppressor for RNAi, and RNA2-encoded protein also lacks RNAi suppression function [50].

Many pathogens of $C$. elegans share the same target tissue, the intestine [47]. Orsay virus is no exception. The intestine in C. elegans consists of 20 cells, holding a proportion of one third of somatic mass and is essential for absorbing nutrient and producing food derived macromolecule [46]. It was found that intestinal cells showed high susceptibility when infected by virus, while few cells from the entire host tissue were infected [46]. Orsay virus affects the intestinal region of nematode which is mainly reflected by the disappearance of cell structures like storage granules and extensive 
convolutions of the apical intestinal border. However, due to lack of the adaptive immune system and specialized immune cells, the defense against virus infection critically depends on epithelial cells. Interestingly, the key anatomical features of the epithelium are conserved between $C$. elegans and mammals [51], which allows studies in C. elegans to be translated to higher species.

Orsay virus infection also triggers the IPR pathway. The exposure to Orsay virus led to upregulation of the Skp, Cullin, F-box (SCF) ubiquitin ligase components, such as the cullin ortholog CUL-6. The ubiquitylation components, the proteasome, and the autophagy pathway are all important for defense against viral infection [52]. However, although C. elegans-Orsay virus and C. elegans-microsporidia interaction pathways both belong to IPR, there is a difference between the two pathogens. The C. elegans retinoic acid-inducible gene (RIG)-I-like receptor DRH-1 was proved to be necessary for inducing IPR when infected by Orsay virus, but not for microsporidia infection or proteotoxic stress [40]. Differentially expressed genes identified responsible for immune response within C. elegans-microsporidia and C. elegans-Orsay virus interactions were also not the same.

The intraspecies susceptibility to Orsay virus of $C$. elegans is highly variant $[53,54]$, as different C. elegans strains have distinct susceptibilities when faced with Orsay virus infection. Studies into the genetic variation to Orsay virus infection revealed that DRH-1, encoding a RIG-I-like helicase, is required for the initiation of an antiviral RNAi pathway and the generation of virus-derived siRNAs (viRNAs) [53]. Wild type Bristol N2 was more resistant than strain JU1580 as it accumulates 50-100 fold less viral RNA inside at young adult stage [24]. The difference was also shown for L2-L4 nematodes, as the final viral load of JU1580 was significantly higher than Bristol N2. It was noted that there were offspring right before measuring viral load. Thus, maybe N2 progeny might lose vertical transmitted infection after several generations, while JU1580 progeny remains infected [54]. In any case, the difference regarding viral susceptibility is affected by genetic variation, thus research on polymorphic loci is essential for identification of causal loci. GWAS analysis is often applied for the detection of polymorphic variants which could link genetic variation with phenotypes. Subsequently, inbred lines and introgression lines can be generated by crossing different wild types of $C$. elegans [55]. For instance, experiments using GWAS and introgression lines proved that a $d r h-1$ polymorphism is involved in viral susceptibility [53]. In summary, based on C. elegans genetic variation studies involving Orsay virus, insight into antiviral immunity in C. elegans was developed and more detail in viral infection and host response was revealed.

\section{Conclusion and Future Outlook}

Quantitative genetic analyses into different C. elegans genotypes of pathogenic microbiota interactions can be complementary to studying interactions in a single genotype. Studying microbiota interactions across multiple genotypes allows for unraveling the genetic architecture of these interactions.

Mapping of genetic variation is an essential tool in investigating the genetic basis of complex traits that underlie the interaction between C. elegans and its associated microbiota. Resources like CeNDR, in combination with QTL studies, could provide more insight of gene function and evolutionary studies. To overcome the limitations of RILs that were derived from a combination of two parental strains (usually Bristol N2 and Hawaii CB4856), multiparent populations like CeMEE and the four parental population panel can improve the power of detecting natural genetic variants [13].

In the future, with the application of advanced methods of quantitative genetics study, genetic variation of $C$. elegans could be explored more to reveal the genetic architecture of variants relating to complex microbiota related traits. This may promote the study of the underlying molecular genetic mechanisms at, for instance, the metabolic and protein levels. Further, it may aid to understand how microbiota influence the fitness of $C$. elegans and how functional genes affect the microbiota interactions. For example, a recent study on nematode trapping fungi (NTF) demonstrated the trap induction, involving $\mathrm{G}$ protein $\beta$-subunit Gpb 1, plays as fitness character in NTF family [56]. A next step would be to combine different microbiota, like bacteria and viruses, in order to assess their 
impact simultaneously. Together, they could be exploited to obtain knowledge on both molecular and evolutionary aspects of host-microbiota interactions, including but not limited to microsporidia, bacteria, and viruses. Thus, it would provide more information on how organisms in nature adjust and evolve in the interaction with its microbiota.

Author Contributions: Y.H. and J.E.K. both wrote the manuscript. All authors have read and agreed to the published version of the manuscript.

Funding: This research was funded by Chinese Scholarship Council grant number 201707720002.

Acknowledgments: Y.H. was funded by the Chinese Scholarship Council. We thank Gorben Pijlman and Lisa van Sluijs for helpful comments and suggestions.

Conflicts of Interest: The authors declare no conflicts of interest.

\section{References}

1. Marsh, E.K.; May, R.C. Caenorhabditis elegans, a model organism for investigating immunity. Appl. Environ. Microbiol. 2012, 78, 2075-2081. [CrossRef]

2. Frezal, L.; Felix, M.A.C. C. elegans outside the Petri dish. Elife 2015, 4, e05849. [CrossRef] [PubMed]

3. Gammon, D.B. Caenorhabditis elegans as an Emerging Model for Virus-Host Interactions. J. Virol. $2017,91$. [CrossRef] [PubMed]

4. Zimmermann, J.; Obeng, N.; Yang, W.; Pees, B.; Petersen, C.; Waschina, S.; Kissoyan, K.A.; Aidley, J.; Hoeppner, M.P.; Bunk, B.; et al. The functional repertoire contained within the native microbiota of the model nematode Caenorhabditis elegans. ISME J. 2020, 14, 26-38. [CrossRef] [PubMed]

5. Schulenburg, H.; Felix, M.A. The Natural Biotic Environment of Caenorhabditis elegans. Genetics 2017, 206, 55-86. [CrossRef] [PubMed]

6. Sterken, M.G.; Snoek, L.B.; Kammenga, J.E.; Andersen, E.C. The laboratory domestication of Caenorhabditis elegans. Trends Genet. 2015, 31, 224-231. [CrossRef]

7. Fierer, N. Embracing the unknown: Disentangling the complexities of the soil microbiome. Nat. Rev. Microbiol. 2017, 15, 579-590. [CrossRef]

8. Johnke, J.; Dirksen, P.; Schulenburg, H. Community assembly of the native C. elegans microbiome is influenced by time, substrate and individual bacterial taxa. Environ. Microbiol. 2020, 22, 1265-1279. [CrossRef]

9. Marchesi, J.R. Advancing microbiome research. Microbiology 2018, 164, 1005-1006. [CrossRef]

10. Cassidy, L.; Petersen, C.; Treitz, C.; Dierking, K.; Schulenburg, H.; Leippe, M.; Tholey, A. The Caenorhabditis elegans Proteome Response to Naturally Associated Microbiome Members of the Genus Ochrobactrum. Proteomics 2018, 18, e1700426. [CrossRef]

11. Gaertner, B.E.; Phillips, P.C. Caenorhabditis elegans as a platform for molecular quantitative genetics and the systems biology of natural variation. Genet. Res. 2010, 92, 331-348. [CrossRef] [PubMed]

12. Gao, A.W.; Sterken, M.G.; Uit de Bos, J.; van Creij, J.; Kamble, R.; Snoek, B.L.; Kammenga, J.E.; Houtkooper, R.H. Natural genetic variation in C. elegans identified genomic loci controlling metabolite levels. Genome Res. 2018, 28, 1296-1308. [CrossRef] [PubMed]

13. Snoek, B.L.; Volkers, R.J.M.; Nijveen, H.; Petersen, C.; Dirksen, P.; Sterken, M.G.; Nakad, R.; Riksen, J.A.G.; Rosenstiel, P.; Stastna, J.J.; et al. A multi-parent recombinant inbred line population of C. elegans allows identification of novel QTLs for complex life history traits. BMC Biol. 2019, 17, 24. [CrossRef]

14. Cook, D.E.; Zdraljevic, S.; Roberts, J.P.; Andersen, E.C. CeNDR, the Caenorhabditis elegans natural diversity resource. Nucleic Acids Res. 2017, 45, D650-D657. [CrossRef] [PubMed]

15. Snoek, B.L.; Sterken, M.G.; Hartanto, M.; van Zuilichem, A.J.; Kammenga, J.E.; de Ridder, D.; Nijveen, H. WormQTL2: An interactive platform for systems genetics in Caenorhabditis elegans. Database 2020, 2020. [CrossRef] [PubMed]

16. Sterken, M.G. Building towards A Multi-Dimensional Genetic Architecture in Caenorhabditis Elegans; Wageningen University: Wageningen, The Netherlands, 2016.

17. Noble, L.M.; Chelo, I.; Guzella, T.; Afonso, B.; Riccardi, D.D.; Ammerman, P.; Dayarian, A.; Carvalho, S.; Crist, A.; Pino-Querido, A.; et al. Polygenicity and Epistasis Underlie Fitness-Proximal Traits in the Caenorhabditis elegans Multiparental Experimental Evolution (CeMEE) Panel. Genetics 2017, 207, 1663-1685. 
18. Schulenburg, H.; Muller, S. Natural variation in the response of Caenorhabditis elegans towards Bacillus thuringiensis. Parasitology 2004, 128 Pt 4, 433-443. [CrossRef]

19. Reddy, K.C.; Andersen, E.C.; Kruglyak, L.; Kim, D.H. A polymorphism in npr-1 is a behavioral determinant of pathogen susceptibility in C. elegans. Science 2009, 323, 382-384. [CrossRef]

20. Glater, E.E.; MRockman, V.; Bargmann, C.I. Multigenic natural variation underlies Caenorhabditis elegans olfactory preference for the bacterial pathogen Serratia marcescens. G3 2014, 4, 265-276. [CrossRef]

21. Balla, K.M.; Lazetic, V.; Troemel, E.R. Natural variation in the roles of C. elegans autophagy components during microsporidia infection. PLoS ONE 2019, 14, e0216011. [CrossRef]

22. Reinke, A.W.; Balla, K.M.; Bennett, E.J.; Troemel, E.R. Identification of microsporidia host-exposed proteins reveals a repertoire of rapidly evolving proteins. Nat. Commun. 2017, 8, 14023. [CrossRef] [PubMed]

23. Balla, K.M.; Andersen, E.C.; Kruglyak, L.; Troemel, E.R. A wild C. elegans strain has enhanced epithelial immunity to a natural microsporidian parasite. PLoS Pathog. 2015, 11, e1004583. [CrossRef] [PubMed]

24. Felix, M.A.; Ashe, A.; Piffaretti, J.; Wu, G.; Nuez, I.; Belicard, T.; Jiang, Y.; Zhao, G.; Franz, C.J.; Goldstein, L.D.; et al. Natural and experimental infection of Caenorhabditis nematodes by novel viruses related to nodaviruses. PLoS Biol. 2011, 9, e1000586. [CrossRef] [PubMed]

25. Zhang, F.; Berg, M.; Dierking, K.; Felix, M.A.; Shapira, M.; Samuel, B.S.; Schulenburg, H. Caenorhabditis elegans as a Model for Microbiome Research. Front. Microbiol. 2017, 8, 485. [CrossRef] [PubMed]

26. Zhang, J.; Holdorf, A.D.; Walhout, A.J.C. C. elegans and its bacterial diet as a model for systems-level understanding of host-microbiota interactions. Curr. Opin. Biotechnol. 2017, 46, 74-80. [CrossRef] [PubMed]

27. Samuel, B.S.; Rowedder, H.; Braendle, C.; Felix, M.A.; Ruvkun, G. Caenorhabditis elegans responses to bacteria from its natural habitats. Proc. Natl. Acad. Sci. USA 2016, 113, E3941-E3949. [CrossRef]

28. Kissoyan, K.A.B.; Drechsler, M.; Stange, E.L.; Zimmermann, J.; Kaleta, C.; Bode, H.B.; Dierking, K. Natural C. elegans Microbiota Protects against Infection via Production of a Cyclic Lipopeptide of the Viscosin Group. Curr. Biol. 2019, 29, 1030-1037. [CrossRef]

29. Moore, R.S.; Kaletsky, R.; Murphy, C.T. Piwi/PRG-1 Argonaute and TGF-beta Mediate Transgenerational Learned Pathogenic Avoidance. Cell 2019, 177, 1827-1841. [CrossRef]

30. Osman, G.A.; Fasseas, M.K.; Koneru, S.L.; Essmann, C.L.; Kyrou, K.; Srinivasan, M.A.; Zhang, G.; Sarkies, P.; Felix, M.A.; Barkoulas, M. Natural Infection of C. elegans by an Oomycete Reveals a New Pathogen-Specific Immune Response. Curr. Biol. 2018, 28, 640-648. [CrossRef]

31. Burton, N.O.; Riccio, C.; Dallaire, A.; Price, J.; Jenkins, B.; Koulman, A.; Miska, E.A.C. C. elegans heritably adapts to P. vranovensis infection via a mechanism that requires the cysteine synthases cysl-1 and cysl-2. bioRxiv 2019. [CrossRef]

32. Masri, L.; Schulte, R.D.; Timmermeyer, N.; Thanisch, S.; Crummenerl, L.L.; Jansen, G.; Michiels, N.K.; Schulenburg, H. Sex differences in host defence interfere with parasite-mediated selection for outcrossing during host-parasite coevolution. Ecol. Lett. 2013, 16, 461-468. [CrossRef] [PubMed]

33. de Bono, M.; Bargmann, C.I. Natural variation in a neuropeptide Y receptor homolog modifies social behavior and food response in C. elegans. Cell 1998, 94, 679-689. [CrossRef]

34. Nakad, R.; Snoek, L.B.; Yang, W.; Ellendt, S.; Schneider, F.; Mohr, T.G.; Rosingh, L.; Masche, A.C.; Rosenstiel, P.C.; Dierking, K.; et al. Contrasting invertebrate immune defense behaviors caused by a single gene, the Caenorhabditis elegans neuropeptide receptor gene npr-1. BMC Genom. 2016, 17, 280. [CrossRef] [PubMed]

35. Bendesky, A.; Tsunozaki, M.; Rockman, M.V.; Kruglyak, L.; Bargmann, C.I. Catecholamine receptor polymorphisms affect decision-making in C. elegans. Nature 2011, 472, 313-318. [CrossRef] [PubMed]

36. Andersen, E.C.; Bloom, J.S.; Gerke, J.P.; Kruglyak, L. A variant in the neuropeptide receptor npr-1 is a major determinant of Caenorhabditis elegans growth and physiology. PLoS Genet. 2014, 10, e1004156. [CrossRef]

37. Chang, H.C.; Paek, J.; Kim, D.H. Natural polymorphisms in C. elegans HECW-1 E3 ligase affect pathogen avoidance behaviour. Nature 2011, 480, 525-529. [CrossRef]

38. Stentiford, G.D.; Becnel, J.J.; Weiss, L.M.; Keeling, P.J.; Didier, E.S.; Williams, B.A.P.; Bjornson, S.; Kent, M.L.; Freeman, M.A.; Brown, M.J.F.; et al. Microsporidia-Emergent Pathogens in the Global Food Chain. Trends Parasitol. 2016, 32, 657. [CrossRef]

39. Balla, K.M.; Luallen, R.J.; Bakowski, M.A.; Troemel, E.R. Cell-to-cell spread of microsporidia causes Caenorhabditis elegans organs to form syncytia. Nat. Microbiol. 2016, 1, 16144. [CrossRef] 
40. Sowa, J.N.; Jiang, H.; Somasundaram, L.; Tecle, E.; Xu, G.; Wang, D.; Troemel, E.R. The Caenorhabditis elegans RIG-I Homolog DRH-1 Mediates the Intracellular Pathogen Response upon Viral Infection. J. Virol. 2020, 94. [CrossRef]

41. Reddy, K.C.; Dror, T.; Underwood, R.S.; Osman, G.A.; Elder, C.R.; Desjardins, C.A.; Cuomo, C.A.; Barkoulas, M.; Troemel, E.R. Antagonistic paralogs control a switch between growth and pathogen resistance in C. elegans. PLoS Pathog. 2019, 15, e1007528. [CrossRef]

42. Zhang, G.; Sachse, M.; Prevost, M.C.; Luallen, R.J.; Troemel, E.R.; Felix, M.A. A Large Collection of Novel Nematode-Infecting Microsporidia and Their Diverse Interactions with Caenorhabditis elegans and Other Related Nematodes. PLoS Pathog. 2016, 12, e1006093. [CrossRef] [PubMed]

43. Luallen, R.J.; Reinke, A.W.; Tong, L.; Botts, M.R.; Felix, M.A.; Troemel, E.R. Discovery of a Natural Microsporidian Pathogen with a Broad Tissue Tropism in Caenorhabditis elegans. PLoS Pathog. 2016, 12, e1005724. [CrossRef] [PubMed]

44. Franz, C.J.; Zhao, G.; Felix, M.A.; Wang, D. Complete genome sequence of Le Blanc virus, a third Caenorhabditis nematode-Infecting Virus. J. Virol. 2012, 86, 11940. [CrossRef] [PubMed]

45. Ashe, A.; Sarkies, P.; Le Pen, J.; Tanguy, M.; Miska, E.A. Antiviral RNA Interference against Orsay Virus Is neither Systemic nor Transgenerational in Caenorhabditis elegans. J. Virol. 2015, 89, 12035-12046. [CrossRef]

46. Franz, C.J.; Renshaw, H.; Frezal, L.; Jiang, Y.; Felix, M.A.; Wang, D. Orsay, Santeuil and Le Blanc viruses primarily infect intestinal cells in Caenorhabditis nematodes. Virology 2014, 448, 255-264. [CrossRef]

47. Jiang, H.; Wang, D. The Microbial Zoo in the C. elegans Intestine: Bacteria, Fungi and Viruses. Viruses 2018, 10, 85. [CrossRef]

48. Yuan, W.; Zhou, Y.; Fan, Y.; Tao, Y.J.; Zhong, W. Orsay delta Protein Is Required for Nonlytic Viral Egress. J. Virol. 2018, 92, e00745-18. [CrossRef]

49. Felix, M.A.; Wang, D. Natural Viruses of Caenorhabditis Nematodes. Annu. Rev. Genet. 2019, 53, 313-326. [CrossRef]

50. Guo, X.; Lu, R. Characterization of virus-encoded RNA interference suppressors in Caenorhabditis elegans. J. Virol. 2013, 87, 5414-5423. [CrossRef]

51. Pukkila-Worley, R.; Ausubel, F.M. Immune defense mechanisms in the Caenorhabditis elegans intestinal epithelium. Curr. Opin. Immunol. 2012, 24, 3-9. [CrossRef]

52. Bakowski, M.A.; Desjardins, C.A.; Smelkinson, M.G.; Dunbar, T.L.; Lopez-Moyado, I.F.; Rifkin, S.A.; Cuomo, C.A.; Troemel, E.R. Ubiquitin-mediated response to microsporidia and virus infection in C. elegans. PLoS Pathog. 2014, 10, e1004200. [CrossRef] [PubMed]

53. Ashe, A.; Belicard, T.; Le Pen, J.; Sarkies, P.; Frezal, L.; Lehrbach, N.J.; Felix, M.A.; Miska, E.A. A deletion polymorphism in the Caenorhabditis elegans RIG-I homolog disables viral RNA dicing and antiviral immunity. Elife 2013, 2, e00994. [CrossRef] [PubMed]

54. Sterken, M.G.; Snoek, L.B.; Bosman, K.J.; Daamen, J.; Riksen, J.A.; Bakker, J.; Pijlman, G.P.; Kammenga, J.E. A heritable antiviral RNAi response limits Orsay virus infection in Caenorhabditis elegans N2. PLoS ONE 2014, 9, e89760. [CrossRef]

55. Van Sluijs, L.; Pijlman, G.P.; Kammenga, J.E. Why do individuals differ in viral susceptibility? A story told by model organisms. Viruses 2017, 9, 284. [CrossRef] [PubMed]

56. Yang, C.T.; Vidal-Diez de Ulzurrun, G.; Goncalves, A.P.; Lin, H.C.; Chang, C.W.; Huang, T.Y.; Chen, S.A.; Lai, C.K.; Tsai, I.J.; Schroeder, F.C.; et al. Natural diversity in the predatory behavior facilitates the establishment of a robust model strain for nematode-trapping fungi. Proc. Natl. Acad. Sci. USA 2020, 117, 6762-6770. [CrossRef] [PubMed]

(C) 2020 by the authors. Licensee MDPI, Basel, Switzerland. This article is an open access article distributed under the terms and conditions of the Creative Commons Attribution (CC BY) license (http://creativecommons.org/licenses/by/4.0/). 